\title{
DANTE XXI: UMA PONTE ENTRE A IDADE MÉDIA E A CONTEMPORANEIDADE
}

\section{DANTE XXI: A BRIDGE BETWEEN THE AVERAGE AGE AND THE CONTEMPORANEITY}

\author{
DANTE XXI: UM PUENTE ENTRE LA EDAD MEDIA Y LA \\ CONTEMPORANEIDAD
}

\author{
Alexandro Buffon \\ Universidade Feevale- \\ sandrobuffon@feevale.br \\ Cristina Ennes da Silva \\ Docente Historia Medieval - Universidade Feevale - \\ crisennes@feevale.br
}

\section{Resumo}

Este estudo tem como tema a obra medieval A Divina Comedia de Dante Alighieri. O objetivo é identificar e analisar a apropriação dos elementos constantes na obra e reinterpretados pela banda Sepultura em seu registro sonoro Dante XXI. Produtos culturais de tempos e sociedades distintas, com características próprias de suas épocas, buscamos compreender semelhanças e diferenças que apresentam, veiculadas, é claro, aos seus respectivos contextos de produção. A análise se dará dentro da seguinte perspectiva: como Dante percebia o tema aqui escolhido em sua época e como a banda Sepultura reinterpreta e atualiza em seu registro sonoro esta visão para os dias atuais.

Palavras-chave: Dante. Heavy Metal. Política.

\begin{abstract}
This study has as subject the medieval work Divine Comedy of Dante Alighieri. The objective is to identify and to analyze the appropriation of the elements constant in the medieval work and reinterpreted by the band Sepultura in its cd Dante XXI. Cultural products of times and distinct societies, with proper characteristics of its times, we search to understand similarities and differences that present, propagated, clearly, to its respective contexts of production. This analysis will be inside of the following perspective: how Dante perceived them at his time and how the band Sepultura reinterprets them and updates it in its sound recording with a vision of the current days.
\end{abstract}

Key words: Dante. Heavy Metal. Politics. 


\section{Resumen}

Este studio tiene como tema la obra medieval de La Divina Comedia de Dante Alighieri. El objetivo es identificar y analizar la propriedad de los elementos que figuran en la obra y reiterpretados por la banda Sepultura en su registro sonido Dante XXI. Los productos culturales de los tiempos y de empresas independientes, con sus proprias caracteristicas de sus tiempos, tratamos de entender las similitudes y diferencias que presentan, distribuido, es claro, a sus respectivos contextos de producción. El análisis se dará dentro de la siguiente perspectiva: como Dante percibía el tema aquí escogido en su época y como la banda Sepultura reinterpreta y atualiza en su registro sonoro esta visión para los días actuales.

Palabras clave: Dante. Heavy Metal. Politica.

\section{INTRODUÇÃO}

A Divina Comédia, de Dante Alighieri permanece até os dias atuais como uma das mais importantes e influentes obras da literatura mundial, misturando elementos da cultura grega com filosofia e dogmas da cultura Cristã vigentes no período em que foi escrita. Inicialmente popularizada pela tradição oral, sua versão do que ocorre após a morte, tornou-se a mais aceita pelo Cristianismo, norteando até hoje nossa visão de como seria a vida pósmorte.

Este artigo faz parte de um projeto maior, onde diversas categorias foram analisadas. Aqui pretendemos espelhar a primeira parte do estudo, onde se busca identificar e analisar as apropriações que a banda de Heavy Metal Sepultura fez da obra de Alighieri em seu registro sonoro Dante XXI, referentes à política, bem como as mudanças na percepção dos temas tratados em ambas as fontes, que por sua vez foram produzidas em épocas distintas, cada uma tendo suas características próprias.

A seleção de produtos culturais que analisaremos neste trabalho se deu também pela possibilidade da comparação entre obras de diferentes épocas, ou seja, séc. XIV e séc. XXI. Isso nos permite refletir a respeito das possíveis alterações existentes, referentes ao pensamento do ser humano ao longo dos séculos, pois segundo Backzo (1985) "todas as épocas têm as suas modalidades específicas de imaginar, reproduzir e renovar o imaginário, assim como possuem modalidades específicas de acreditar, sentir e pensar.” (p.309) 
Ao juntar literatura e música, dois produtos culturais que, no caso deste estudo foram construídos em diferentes épocas e lugares, espelhando a cultura dos povos e sociedades que dele fizeram parte, estamos assim unindo dois imaginários separados pelo tempo, mas unidos e influenciados pelas ideias

\section{A DIVINA VIDA E OBRA DE DANTE ALIGHIERI}

Descendente de uma família da baixa nobreza, Dante Alighieri nasceu em maio de 1265, na cidade de Florença, Itália. Seu avô era um próspero homem de negócios sempre em contato, através do comércio, com a rica aristocracia do local. Fato este que proporcionou a Dante uma boa educação, apesar das dificuldades financeiras que sua família enfrentava. Sua educação feita em escolas privadas da cidade de Florença incluiu a leitura de grandes clássicos da época, como Virgilio ${ }^{1}$ e Ovideo $^{2}$. Órfão de mãe, Dante encontra aos nove anos de idade a menina Beatriz Portinari, por quem se apaixona, fazendo dela a sua musa e personagem de vários de seus poemas. Na época que Dante viveu os casamentos, meio pelo qual a Igreja Católica usava como forma de controle dos fiéis, eram arranjados entre as famílias. Assim, Dante aos 12 anos já sabia que deveria se casar com uma moça da família Donati, fato ocorrido quando em 1285, casa-se com Gemma, mãe de seus quatro filhos.

Existem hoje poucos registros sobre a vida do poeta. Segundo Bonnel (2002) seu nome consta apenas uma vez nos registros da cidade de Florença, na lista dos cidadão condenados a pena de morte pelo governo dos guelfos negros. Valendo-nos das palavras de Raul de Pollillo (1952), podemos então afirmar

Dante é algo assim como uma sombra. Uma sombra vasta - uma sombra titânica, se preferir - mas apenas uma sombra que se espalma, enigmática e inevitável, sobre seis séculos de civilização ocidental. A sombra domina o tempo, desde a Idade Média até aos nossos dias. (p.5)

Além de escritor, Dante dedicou boa parte de sua vida a política, onde exerceu cargos de extrema importância em sua cidade natal. Atividade esta que também o levou ao exílio, onde escreveria sua obra máxima, que serve de base para nossa pesquisa: A Divina Comédia.

\footnotetext{
${ }^{1}$ Mestre e guia de Dante em sua viagem pelo Inferno e pelo Purgatório, Virgílio é considerado um dos maiores poetas de Roma. Nascido em 70 a.c, sua obra mais conhecida é a Eneida. (Martins, 1979)

${ }^{2}$ Poeta romano, nascido em 43 a.c., conhecido como autor de Herodes. Foi influente na Antiguidade tardia e na Idade Média. (Bonnell, 2002)
} 
A obra narra a viagem do poeta ao mundo dos mortos, e subdivide-se em três partes, que são pela ordem: o Inferno, local aonde vão os que pecaram e não se arrependeram do ato cometido, o Purgatório, recinto reservado para quem pecou, mas se arrependeu antes da morte e o Paraíso que é dividido em nove céus fazendo referências a astros do sistema solar como este era conhecido na Idade Média, possuindo toda paisagem descrita pelo poeta em luzes. Os três recintos formam um conjunto de representações medievais, que sintetizam a visão do além existente no período medievo.

As sociedades através dos tempos costumam atribuir significados ao mundo em que vivem, expressando este entendimento em ações. Problematizando a questão José Roberto Mello (1992) nos afirma que "Saber como os homens viviam é importante, mas tão mais importante é saber como eles pensavam e como representavam mentalmente a realidade existencial”. (p.7)

De acordo com Chartier (2002) não há pratica ou estrutura social que não seja produzida pelas representações. Sendo então, por meio destas, que os indivíduos e os grupos sociais acabam dando sentido as suas realidades. Produzindo-as, estas sociedades pensam e constroem suas vidas, tornando-se assim presentes no dia a dia destes grupos. E continua nos explicando que

[...] as tentativas feitas para decifrar diferentemente as sociedades, penetrando o dédalo dessas relações e das tensões que as constituem a partir de um ponto de entrada particular (um acontecimento, obscuro ou maior, o relato de uma vida, uma rede de práticas especificas) e considerando que não há pratica ou estrutura que não seja produzida pelas representações, contraditórias e afrontadas, pelas quais os indivíduos e os grupos dão sentido a seu mundo ( p.66).

Com grande importância na consolidação do imaginário medieval referente ao pós vida, o poema foi escrito com cunho altamente religioso, já que segundo Zampognaro (2011) Dante quando de sua escrita partiu de princípios cristãos para sua elaboração. Portanto se torna pertinente que se tenha conhecimento a respeito da época em que foi escrita, para poder melhor apreciá-la.

Ao se estudar e pesquisar um período como a Idade Média, devemos lembrar que até hoje, poucas épocas sofreram e sofrem tamanho preconceito e são vitimas de tantas ideias estereotipadas como o período em questão. Cercado de mitos e lendas, a Idade Média durante muito tempo foi apresentada como sendo uma época "soterrada de sangue, ignorância e 
fanatismo religioso" (INÁCIO, 1994, p.9). De acordo com Huizinga (2013) tem-se a ideia de que o homem medievo teria vivido no momento mais triste da humanidade, pois

Onde quer que se procure o legado dessa época - nos historiadores, nos poetas, nos sermões, nos tratados religiosos e em documentos notariais-, com poucas exceções, encontramos apenas lembranças de brigas, ódios, maldade, ganância, selvageria e miséria. (p.47)

Ao produzir um poema onde um pedaço de cada um de nós é espelhado, Dante cria uma obra que nas palavras do jornalista gaúcho Eduardo Sterzi (2008), “[...] como nenhum outro texto, a não ser a Bíblia, tornou-se uma espécie permanente de imagens a disposição de todos, mesmo daqueles que jamais leram um único verso escrito por Dante”. (p. 25)

Segundo o escritor Marco Lucchesi (2013) a obra “[...] é um organismo vivo, como as grandes obras. Vive uma vida plena, ao contrário de seus críticos e leitores, que temos data marcada. Não há mais Dante, que subsiste apenas em virtude da obra que o recria.” Assim, sua figura se expande, mesmo após sua existência terrena.

\section{SEPULTURA: DO INICIO AO APOGEU}

Iniciamos nossa jornada na década de 70 e 80, período em que no Brasil chegavam poucos shows internacionais. Nos anos setenta, de forma precária, vieram bandas que no exterior já tinham seu nome consolidado como Led Zepellin, Deep Purple e Black Sabath ${ }^{3}$, reunindo ao seu redor os chamados fãs do rock pauleira. Já nos ano início dos anos 80, a situação começou a se modificar, mesmo que de forma sutil. De acordo com Janotti (2004) estes eventos foram de extrema importância para a popularização do gênero

Todos estes shows foram grandes acontecimentos midiáticos, que, além do congraçamento dos fãs, também possibilitaram o surgimento de uma nova geração de adeptos do rock pesado, uma vez que esses eventos tiveram uma ampla cobertura das grandes cadeias televisivas, destacando aspectos exóticos dos músicos e da sonoridade metálica. (p.36)

No Brasil a formação de bandas que pudessem ser classificados legítimos representantes do Heavy Metal ou do Rock era ainda insipiente, e o que se mostrava nos

\footnotetext{
${ }^{3}$ Precursores do Heavy Metal, nos anos 70 e 80, tendo influência crucial no desenvolvimento e popularização do estilo.
} 
meios de comunicação era extremamente estereotipado, com a predominância do sensacionalismo, ironia e sempre ressaltando aspectos exóticos e lendários.

Foi neste contexto que em Minas Gerais, no ano de 1983, os irmãos Igor e Max Cavalera, decidiram transformar sua paixão pelo "rock pesado" em algo mais do que a simples audiência de shows, raros, e audição dos poucos discos que chegavam ao Brasil. Junto a dois amigos de escola, Paulo Jr. e Jairo Guedez, decidem formar uma banda cujo nome foi concebido e inspirado na canção "Dance on your grave" da banda Motorhead": Sepultura. Começava assim os primeiros passos da considerada hoje segundo Batalha (2013) "o maior nome do metal brasileiro de todos os tempos". (p.114)

Os shows de quem se aventurava por este gênero musical considerado marginal eram sempre feitos em bares, em universidades ou em algum festival modesto em cidades espalhadas pelo território nacional. E foi justamente em um destes eventos, que o Sepultura chamou a atenção do dono da gravadora Cogumelo Records ${ }^{5}$, que ao vê-los tocando contratou-os. Lançaram então o álbum chamado "Bestial Devastation e a boa vendagem e repercussão fizeram com que a gravadora Roadrunner oferecesse um contrato de sete anos para a banda. Firmado o contrato, gravaram em nove dias o álbum "Beneath the Remains" que segundo Torres (2014) os colocou definitivamente no mapa do mundo do Heavy Metal. No mesmo ano lançaram "Arise", colocando-os em igualdade, em termos de vendagem, com os grandes nomes do gênero no mundo.

Porém em meio à promoção mundial do disco "Roots Bloody Roots", morreu de forma prematura aos 21 anos, o filho do primeiro casamento de Gloria Bujnowski, esposa de Max Cavaleira. A banda entra então, em conflito, pois a maioria dos integrantes não queria cancelar a agenda de shows que já haviam sido programados. Andreas Kisser, Igor Cavalera e Paulo Junior, decidiram demitir a empresária Glória, alegando que, sendo ela esposa de Max Cavalera, deixava-o sempre em primeiro plano na hora a promoção da banda. Max então em Dezembro de 1996 anunciou sua saída oficial do Sepultura deixando a banda em um período de crise e transição.

Após um período de incertezas, onde foi escolhido um novo vocalista, o americano Derrick Green, lançaram em 2006, o álbum Dante XXI, baseado na obra do poeta Dante Alighieri e receberam elogios tanto da crítica como do público, que considerou a obra, uma

\footnotetext{
${ }^{4}$ Banda inglesa, formada em 1975, considerada uma das maiores referencias do Heavy Metal mundial. Disponível em http://www.portaldorock.com.br/destaquebandas9.htm Acesso em 15.out.2014.

${ }^{5}$ Gravadora funda da em 1980, em Belo Horizonte, inicialmente surgiu como uma loja de discos, passando a produzi-los a partir do ano de 1985. Mais informações estão disponíveis em <http://www.cogumelo.com/pt/>. Acessado em Outubro/2014.
} 
volta aos velhos tempos da banda. O álbum se compõe de quinze canções que são separadas por recinto, assim como a obra que foi sua fonte de inspiração.

O registro sonoro Dante XXI trouxe até nós o que o vocalista da banda, Green (2008) diz ser uma trilha sonora particular para a obra de Alighieri, fazendo com que a audiência moderna, acostumada com os grandes avanços tecnológicos das últimas décadas do século pudesse ter acesso à obra em outro formato.

Percebido na sua maioria das vezes com extrema subjetividade, o registro sonoro, que faz parte do grupo denominado fontes audiovisuais, junto com o cinema e a televisão, deve ser percebido de acordo com Napolitano (2005) "em suas estruturas internas de linguagem e seus mecanismos de representação da realidade, a partir de seus códigos internos”. (p. 236)

Unir em um mesmo trabalho uma obra literária e um registro sonoro é debruçar-se sobre dois meios de expressão que tendo portanto, características próprias, expõem a peculiaridade da sociedade e do tempo que as produziu. Cada uma das sociedades, dentro de suas características, pensou sobre os temas contidos nos documentos analisados, conforme suas particularidades e com as convicções de seu tempo.

\section{POLITICA: DA IDADE MÉDIA AOS DIAS ATUAIS}

Na obra A Divina Comedia a política ocupa parte fundamental de sua estrutura. O período em que Dante viveu sua experiência neste setor caracterizou-se pela disputa entre o Imperador e o Papa. Em Florença, a política representava o interesse das famílias e era dividida entre duas facções, denominadas Guelfos e Guibelinos

Os Guelfos, partido ao qual o poeta se une, acabaram se partindo em dois grupos: Brancos e Negros. Os Brancos sustentavam uma postura moderada, eram abertos as camadas populares e defendiam uma autonomia quanto ao domínio do Pontífice Católico, opondo-se a sua interferência na política da cidade. Já os Guelfos Negros, estavam intimamente comprometidos com os interesses do papado e das famílias dominantes. Constituídos pela baixa nobreza apoiavam o Papa contra as ambições do Imperador.

Dante despontou neste conturbado cenário político aos 31 anos e logo após foi eleito como um dos seis Priores ${ }^{6}$ do conselho da cidade. Durante o breve período que esteve no cargo posicionou-se favoravelmente ao exílio de lideres extremistas de ambas as facções, a fim de facilitar o processo de pacificação da região. Porém, integrantes da facção dos Guelfos

\footnotetext{
${ }^{6}$ Segundo Martins (1979) Priore era a suprema magistratura política de Florença e foi segundo o próprio Dante, a eleição ao priorato, a origem de sua desgraça.
} 
Negros, que foram exilados, intercedem junto ao Papa Bonifácio VIII, para que a sentença seja revogada. Dante partiu então a Roma para se reunir, na função de embaixador, junto ao Pontífice, para que este não deixe a situação ir adiante.

Enquanto permanecia em Roma, os Guelfos Negros tomaram acidade e ao retornar, Dante foi avisado das denúncias que pesavam contra ele. Seus adversários o condenaram, segundo Zampognaro (2011) acusando-o de corrupção, a pagar uma multa de cinco mil florins e dois anos de prisão, além de sua interdição perpétua dos ofícios públicos, junto com outros integrantes do partido.

Dante não se defendeu, não pagou a multa, nem se apresentou para receber as acusações formalmente. Por isso, mais uma vez foi condenado e de acordo com as palavras de Pollillo (1952) a pena consistiu em ser queimado vivo em praça pública, já que seu posicionamento abertamente contrário ao poder que a Igreja Católica vinha acumulando, foi considerado além de corrupto, herético. Em consequência disso, o poeta escolheu viver no exílio, encerrando sua vida pública naquele momento.

Em sua obra, Dante fala da desintegração política que a cidade de Florença passou, fato crucial para organização de seu poema. Segundo Eduardo Sterzi (2008

[...] um dos aspectos distintivos da vida de Dante foi seu alto envolvimento na política florentina e italiana de seu tempo. Poucos poetas de grandeza comparável (se há algum...) tiveram uma participação política tão destacada: Dante, não esqueçamos, chegou a ser, ainda que por breve período, um dos administradores principais de sua cidade natal, à época uma das cidades mais importantes da Europa. (p.27)

As músicas que se enquadram nesta categoria são: "Dark Wood of Error" e "False" representando o Inferno, "Óstia" que por sua vez, faz parte do segmento dedicado ao Purgatório.

A primeira canção a ser analisada chama-se "Dark Wood of Error", que se passa imediatamente antes de Dante entrar no Inferno. O trecho da canção escolhido para esta análise é o seguinte: The beast from the Uk/ the beast from US/ The ONU beast was the unleashed/To solve the problems in the world/But they dont. Que podemos traduzir assim: A besta do Reino Unido/A besta dos Estados Unidos /A besta da ONU foi desencadeada/ Para solucionar os problemas/ Do mundo, mas não o fizeram. Aqui é feita uma referencia as três animais que Dante encontra no inicio da sua obra e ao tentar abandonar a floresta escura em que se encontra as feras descritas pelo poeta barram-lhe a saída: 
Quase ao começo da subida aberta / Eis vi uma pantera, ágil, fremente / De pele marchetada recoberta / Do rosto sempre se me punha à frente / A tal ponto o caminho me impedindo / Que eu tinha que recuar constantemente. (ALIGHIERI, 1979, Inferno, Canto I, p. 102, Tradução Cristiano Martins).

Neste trecho o poeta faz alusão a uma pantera, que encontra em seu caminho, e segundo Pollillo (1952) seria uma representação do pecado da luxúria, o qual Dante se entrega após a morte de Beatriz. A luxúria se assemelharia a uma pantera em sua agilidade, tendo o mesmo impulso que este pecado toma de assalto os homens. As manchas pequenas de seu corpo seriam então os outros males que vem a reboque deste maior.

Já para Zampognaro (2011) e Martins (1979) o animal é visto como representante da cidade de Florença, que expulsou Dante de seu território. Neste aspecto político, as manchas seriam os partidos políticos menores que habitavam a cidade e a maltratavam.

Em outro momento Dante refere-se ao outro animal, um leão, que cruza por seu caminho

Na alta manhã, na plácida estação / Mas não sem que eu tornasse ao desalento / Ante a súbita vista de um leão / Parecia raivoso, a juba ao vento / Vir contra mim, de jeito tão nefando / Que até o ar se crispava, num lamento. (ALIGHIERI, 1979, Inferno, Canto I p.104, Tradução Cristiano Martins)

As interpretações feitas ao logo dos anos para este animal também são diversas. Para Pollillo (1952) o leão posto ali pelo poeta faz referência ao orgulho, à soberba e a inveja. Existem interpretações que associam o leão a figura de Carlos de Valois, que foi chamado a Florença, quando da estadia de Dante em Roma, para tomar a cidade junto com os Gelfos Negros, partido político contrário ao de Dante, conforme mencionado anteriormente. A seguir o poeta narra o encontro com o terceiro animal que cruza seu caminho

Seguiu-se magra loba, demonstrando / Á pele os ossos, e que á ira incontida / A muita gente andou exterminando / Veio-me um senso tal de despedida / ante a aparência rápida da fera / Que perdi a esperança na subida. (ALIGHIERI, 1979, Inferno, Canto I, p.104, Tradução Cristiano Martins)

Mais uma vez várias interpretações são feitas a respeito do último animal que cruza o caminho de Dante. A magra loba representa segundo Pollillo (1952) a avareza, pecado que Dante inúmeras vezes acusou pertencente à Igreja e ao poder que os papas teriam dentro dela. Dante tem como teoria que a decadência de Florença deveu-se, em parte, a opulência excessiva de 
alguns. Também é feita uma alusão à fundação de Roma por Rômulo e Remo, que foram alimentados por uma loba.

Ao longo da História muito se tem escrito e debatido a respeito do que representaria os três animais que Dante coloca como empecilho para que consiga prosseguir em seu caminho. Deve-se ressaltar aqui que Dante, neste mundo onde esta preste a entrar é apenas um simples mortal, portanto sujeito a todos os temores, e estes podem ter sido retratados nestes animais.

$\mathrm{Na}$ composição analisada de autoria de Andreas Kisser, a banda faz referencia aos Estados Unidos, ao Reino Unido, na figura principal da Inglaterra e a ONU, como representações políticas que aparecem para resolver problemas, mas não o fazem, tendo inclusive participação direta no que a banda julga como grandes problemas e tragédias do século XXI.

Ao citar "The beast from UK", a banda faz referência ao Reino Unido, formada pelos países da Inglaterra, Escócia, País de Gales e Irlanda do Norte. Tendo como chefe de Estado a rainha Elisabeth, sua sede fica na Inglaterra, sétima economia mundial, rainha dos mares durante a época colonial e o primeiro país a se industrializar. Foi considerada a principal potência mundial, fato que se modificou após as duas guerras mundiais e atualmente possui cadeira permanente no Conselho de Segurança das Nações Unidas.

Quando menciona "The beast from US", a banda faz referência aos Estados Unidos, personagem constante ao longo da obra. Ao ligar a figura do leão ao país norte americano, temos aqui a representação da soberba e da violência em sua mais clara associação. Ao longo de sua obra a banda cita o país e seus governantes, em especial George Bush, como responsáveis por parte dos grandes males de nossa sociedade.

País que provoca ódio, uma potência que traz para si a culpa de boa parte das coisas que ocorrem de bom ou ruim no mundo, possui para muitos a visão do local onde tudo ocorrerá de forma correta e o sucesso será alcançado. Tem em seu "American way of life”, um estilo de vida que já foi base e modelo para civilização ocidental. Com as bombas de Hiroshima e Nagazaki, a Guerra do Vietnã, o poderio naval e militar do país, a criação do FMI, que regula os investimentos mundiais, e sua maciça influência na cultura de outros locais, os Estados Unidos selam de vez sua imagem negativa perante boa parte do mundo.

A terceira besta citada na letrada canção faz referência a ONU. Ao indicar "The UN beast was the unleashed”, a banda refere-se à Organização das Nações Unidas, fundada em 1944, oficialmente criada como sendo um órgão de cooperação internacional para manejar conflitos e interesses internacionais. Dotada de constituição, a Carta das Nações Unidas, que tem por finalidade regular as relações entre estes Estados, tem como membros permanentes China, 
França, Rússia, Reino Unido e Estados Unidos. Possui também, dez membros temporários, eleitos a cada dois anos. Seus membros permanentes são todos potências nucleares. Chamados de "União Nuclear" são acusados de julgar e decidir segundo seus interesses.

Sua muitas vezes incapacidade para atuar em genocídios, e mortes de seus próprios membros como o brasileiro Sergio Vieira de Mello, mais as não sanções aos Estados Unidos, já que dois terços de seu orçamento vêm daquele país, acabam gerando criticas profundas a instituição.

Sendo assim, a banda Sepultura a coloca como uma das três bestas que Dante encontra em seu início de jornada, junto com outros dois países, curiosamente também membros de seu Conselho de Segurança.

A banda cria aqui representações que como Chartier (2002) nos diz são determinadas pelos interesses particulares de seus integrantes, que possuem uma visão crítica referentes aos países citados e fazem em suas canções uma forma de externar esta opinião. As representações são apropriadas e externadas por instituições que possuem uma força coletiva, portanto ao transformar as feras que impedem a saída de Dante da selva escura em países, entende-se que a banda quer que o ouvinte de suas canções compartilhe seu discurso.

A segunda canção escolhida para nossa análise chama-se "False", com letra de Andreas Kisser. Vale ressaltar que nem sempre a banda descreve de maneira linear o que ocorre na obra que serve como base para seu cd. Em muitos casos toma-se uma liberdade poética e cria-se um mundo a partir das ideias descritas por Dante em seu poema.

Embora cite elementos existentes na obra, não traz ligações diretas com a jornada que Dante empreende em sua narrativa. A banda possui uma tradição, em suas composições de fazer fortes críticas aos governos dos países que por terem poder econômico ditam muitas vezes as regras da política mundial. A música em questão, situada no círculo onde pagam por seus pecados quem praticou fraude e peculato em vida, trata da aversão que os membros da banda possuem pelo presidente norte americano George $\mathrm{Bush}^{7}$, eleito pela primeira vez ao cargo em 2000.

\footnotetext{
${ }^{7}$ Nascido em 1946, o americano George Bush, governou os Estados Unidos entre 2001 e 2009, tornando-se o $43^{\circ}$ presidente americano. Filho do também presidente George H. Bush, foi eleito governador do Texas em 1994 e 1998, sendo o primeiro governador reeleito pelo Estado.
} 
Assim, sendo o presidente americano sua fonte de inspiração e seu personagem principal, nos é mostrado como sendo alguém, do ponto de vista dos integrantes da banda, corrupto e que causa danos à sociedade.

Ao citar na canção frases como: You think you rule all/ you made it all wrong/ creating more frauds/ your mask will soon fall. Que podemos traduzir como: Você pensa que comanda tudo/ Você fez tudo errado/ criando mais fraudes/ a sua mascara vai cair em breve.

A banda faz uma alusão à acusação de fraude nas eleições ocorridas em novembro de 2000 em que Bush recebe 539.898 votos a menos que seu adversário Al Gore e mesmo assim foi eleito o presidente naquele pleito, quando a Suprema Corte Americana, validou a apuração da Flórida, após 40 dias de sua realização.

Segundo o vocalista da banda Derrick Green (2008), "O fato é que esta pessoa, George W. Bush, fraudou as eleições do maior Império atualmente, os EUA, e manipula outros países como somente o Império Romano fazia".

Assim é feita pela banda uma atualização para os dias de hoje dos assuntos e problemas tratados por Dante, que ao entrar na sétima e oitava vala do oitavo circulo do Inferno, chamado Malebolgue. "Cercado de muralhas de pedra em férreo colorido e na rocha escavado" (ALIGHIERI, 2003, p.76, tradução Fábio Alberti), vê sendo punidos os fraudadores.

Ainda segundo Green (2008), Alighieri estava insatisfeito com o abuso de poder e a corrupção da política de sua época. Após a análise da canção citada, pode-se concluir que a banda hoje coloca como atual a mesma situação que Dante expôs em sua obra literária, apenas transferindo a política corrupta de Florença para a sala da presidência dos Estados Unidos. Temse aqui uma modificação na representação feita pelo autor na Idade Média, para os dias atuais, quando tomando para si o que foi escrito, atualiza-se e expõem em um contexto diferente os mesmos problemas.

Registra-se também que ao longo da canção são feitas referências a dois recintos encontrados no Inferno, pela segunda vez o Molebolgue, já descrito e a Judeca. A Judeca, quarto recinto do nono circulo, é o posto mais baixo do local, onde mora Lúcifer, e onde o sofrimento é maior que em todo o resto, devido a proximidade do "Imperador do reino doloroso" (ALIGHIERI, 2003, p.142, tradução Fábio Alberti) e por estarem os pecadores que ali foram encaminhados, presos ao gelo, gemendo, no lago Cócito, ainda conscientes.

Ao mencionar na letra da canção "Judeca is your homel Judeca é sua casa” a banda compara a morada do presidente americano, a Casa Branca, ao mais local mais baixo do Inferno, 
onde Lúcifer reside como seu regente, e assim faz também uma associação às duas figuras, o presidente americano George Bush, chefe maior da Casa Branca, e a Lúcifer regente da Judeca ${ }^{8}$.

Aqui mais uma vez a banda se apropria de elementos postos pelo poeta em sua obra, atualizando-os para os dias atuais para conseguir expressar sua mensagem, dando sentido a suas ideias e ideologias. De acordo com Castor Bartolomé Ruiz (2003) este dar sentido é uma forma que as pessoas, ao produzirem discursos conseguem significar o mundo em que vivem, dando sentido as suas realidades. Segundo o autor este sentido “...é criado sempre a partir do desejo. Os sentidos simbólicos que a pessoa cria para as coisas, para as experiências de vida, assim como para o mundo em geral, entrelaçam-se formando redes de significados.” (2003, p.60)

Surgem assim às representações que como cita Chartier (2002) aspiram à universalidade, e são na verdade determinadas pelo interesse particular de quem as produz. A banda com sua notória aversão a política exercida pelos Estados Unidos, cria assim um discurso contra o mesmo para chegar a seus ouvintes e exercer uma influência no imaginário contra o país americano.

Entende-se então que a banda Sepultura, ao construir para si um discurso contra a América, faz das representações criadas em sua obra um meio de legitimação das ideias proferidas por eles, já que segundo Pesavento (2008) as representações servem para expressar discursos e imagens, criando uma representação do mundo, tendo força integradora e coesiva.

A última canção analisada neste estudo chama-se “Óstia”.Nela a banda faz um apanhado da situação política e dos políticos em geral. Estamos no Purgatório, local onde já se faz presente a esperança, e podemos apontar como característica neste trecho e nesta interpretação da música escolhida: Those fools are the ones we vote for/The kings and rules of negligence/(...)I thought the worst that/ I thought the worst that past, que podemos traduzir como: Esses são os tolos que nós votamos/ Os reis e as regras da negligência,/ (...) Eu pensei que o pior,/ Eu pensei que o pior tinha passado.

Verifica-se então uma referência a eleições e aos políticos que se candidatam e que disputam o voto da população e acabam sendo negligentes para com seus eleitores.

Pode-se também fazer uma associação à reeleição de George Bush em 2004. A banda sinaliza que o primeiro mandato do Presidente teria sido ruim e ao terminar seu período no cargo, este ciclo teria então findado. Porém ele é reeleito, vencendo com 50,7\% dos votos contra o democrata John Kerrry.No momento em que a letra nos diz Can not believe/ $i$ couldn't escape/

\footnotetext{
${ }^{8}$ O nome Judeca vem de Judas Escariotes, traidor de Jesus Cristo, e ali estão os que pecaram pela corrupção e fraude, trazendo assim mais associações com a situação dos Estados Unidos.
} 
No chance to leave this plague, que podemos traduzir como: Não é possível acreditar / que eu não poderei escapar/ Sem chance de sair desta praga Analisamos a frase em relação a uma tentativa de achar uma saída para a situação posta, com mais uma vez Bush estar na Presidência americana.

Ainda na canção "Óstia”, podemos notar que há o uso de elementos do Purgatório dantesco. A frase "Hoping for prayers in the world", traduzido como "na espera de orações do mundo" é uma referência ao ato descrito no purgatório pelo poeta a respeito da estadia das almas que ali se encontram. Elas que ali estão podem diminuir sua estadia naquele recinto, se por ventura, quem em terra ficou, orar por elas. Por isso em várias passagens da obra, as almas com quem Dante se deparava e conversava pediam que ele avisasse aos familiares que orassem por elas enquanto estivessem vivos, pois isso diminuiria sua permanecia ali e os elevaria logo ao Paraíso. Na canção analisada vemos uma referência ao ato explicitado acima.

\section{CONSIDERAÇÕES}

Neste trabalho nosso objetivo foi identificar e analisar as diferentes formas que a banda Sepultura em seu registro sonoro Dante XXI, produzido no ano de 2006, apropriou-se de elementos e ideias da obra medieval A Divina Comédia de Dante Alighieri, e os reinterpretou para audiências modernas. Ao trazer a viagem de Dante pelos ambientes do pósvida para os nossos dias, as ideias divulgadas pela banda muitas vezes estavam expostas de forma clara, possibilitando ao ouvinte um entendimento imediato.

Ao analisarmos a questão política, a principal característica que se fez notar é a critica ao governo americano, que por sinal é também personagem de outras obras do Sepultura. Ao dirigir ao ex-presidente George Bush severas criticas e acusações através de suas letras, a banda chega ao ponto de relacioná-lo com Lúcifer e transformar a Casa Branca no Malebolgue, local onde pagam por seus pecados, no Inferno, os que cometeram fraude. Guerras, atentados, cerceamento de liberdade, fraude nas eleições, tudo foi matéria prima para a banda expor, segundo suas convicções, o cenário político existente na época em que o cd foi produzido.

Em sintonia com Dante, que descreve o lado negativo da política praticada na época em que escreveu sua obra, o registro sonoro Dante XXI traz a Florença corrupta e repleta de vícios para o cenário atual, tendo os Estados Unidos como seu principal representante, fazendo uso do imaginário atual a respeito da nação americana, tratando-a como uma superpotência que domina o mundo e dele têm total controle. 
Notou-se aqui que ao relacionar aos Estados Unidos, na figura de seu presidente a culpa por vários males da humanidade, a banda fez uso de um imaginário coletivo presente em nossos dias a respeito do país. Maffesoli (2001) nos diz a respeito deste tema, que o imaginário coletivo supera o individual, pois este por mais presente que seja sempre irá corresponder ao que pensa o grupo no qual está inserida a pessoa.

Ao longo da história, as culturas foram se transformando, e ao fazer uma análise sobre produtos resultantes delas, temos que levar em conta a riqueza e multiplicidade das formas existentes em cada realidade, em cada época e perceber, então, a lógica dentro das sociedades que as produziram para que então façam sentido. São nas palavras de Chartier (2002) processos dinâmicos, que criam então, novos costumes, e para quem se apropria destes produtos, novos usos.

Assim, tanto Dante Alighieri, como a banda Sepultura, inserem-se em seus próprios tempos, em suas próprias concepções de mundo e submetem-se as transformações e realidades que estavam submetidos quando da escrita de suas obras, pois de acordo com Ruiz “A teia de significados socialmente instituídos é diferente e inédita em cada sociedade, pois cada grupo social recria o mundo com um sentido novo. “(2003, p.61)

Como nos diz Lucchesi (2013) "O Dante personagem continua mais vivo do que nunca e mora em toda parte, em todas as línguas, em todos os domínios do planeta" (p.14). E por mais que épocas e imaginários se sucedam, percebemos que muitas das ideias que o autor coloca em suas páginas, ainda estão presentes em nossa vida.

\section{REFERÊNCIAS}

ALIGHIERI, Dante. A Divina Comédia. Trad. Fábio M. Alberti. São Paulo, SP: Nova Cultural, 2003.

de São Paulo, 1979 .

A Divina Comédia. Trad. Cristiano Martins. São Paulo: Editora da Universidade

BACZKO, Bronislaw. A imaginação social. In: LEACH, Edmund et al. Anthropos-Homem. Lisboa, Imprensa Nacional/Casa da Moeda, 1985.

BATALHA, Ricardo. Sepultura: Novo álbum em Outubro. Revista Road Crew -HeavyMetal\& Classic Rock.São Paulo, SP: nº 175, p. 9, Agosto/2013.

BONNELL, Robert. Dante, O Grande iniciado: uma mensagem para os tempos futuros. São Paulo: Madras, 2002. 
CHARTIER, Roger. À beira da falésia: a história entre certezas e inquietudes. Porto Alegre, RS: UFRGS, 2002.

COGUMELO RECORDS. Disponível em <http://www.cogumelo.com/pt/>. Acessado em 17 out. 2014.

FRANCO JUNIOR, Hilário. A Idade Média: Nascimento do Ocidente. São Paulo, SP: Brasiliense, 2006.

GREEN, Derrick. E-mail interview.In:TEUTSCH, Matthew. Dante in a Modern Context: A Review of Sepultura's Album Dante XXI. Latch: A Journal for the Study of the Literary Artifacts in Theory, Culture or History, v. 1, 2008.

HUIZINGA, Johan. O outono da Idade Média. São Paulo: Cosac Naify, 2013.

INÁCIO, Inês C., DE LUCA, Tânia Regina. O pensamento Medieval. São Paulo, SP: Ática, 1994.

JANOTTI JR, Jeder. Heavy metal com dendê: rock pesado e mídia em tempos de globalização. Rio de Janeiro, RJ: Editora E-papers, 2004.

KARNAL, Leandro; TATSCH, Flavia Galli. A memória evanescente. O historiador e suas fontes. São Paulo: Contexto, 2009.

KISSER, Andreas. E-mail interview. In: TEUTSCH, Matthew. Dante in a Modern Context: A Review of Sepultura's Album Dante XXI. Latch: A Journal for the Study of the Literary Artifacts in Theory, Culture or History, v. 1, 2008.

LUCCHESI, Marco. Nove cartas sobre a Divina Comédia: navegações pela obra clássica de Dante. Rio de Janeiro: Fundação Biblioteca Nacional, 2013.

MAFFESOLI, Michel.o Imaginário é uma realidade. (Entrevista) In: Revista FAMECOS, Porto Alegre, $\mathrm{n}^{\circ} 15$, agosto de 2001.

MARTINS, Cristiano. A Vida atribulada de Dante Alighieri. In: Alighieri, Dante. A Divina Comédia. São Paulo: Editora da Universidade de São Paulo, 1979.

MELLO, José Roberto. O Cotidiano do imaginário medieval. São Paulo, SP: Contexto, 1992.

NAPOLITANO, Marcos. A História depois do papel. In. PINSKY, Carla Bassanezi (Org.). Fontes Históricas. 3. ed., São Paulo: Contexto, 2005.

PESAVENTO, Sandra Jatahy. História \& História Cultural. Belo Horizonte: Autêntica, 2008.

POLLILLO, Raul de. A Guisa de justificação. In: ALIGHIERI, Dante. A Divina Comédia. Rio de Janeiro: W.M. Jackson INC. editores, 1952.

RUIZ, Castor Bartolomé. Os paradoxos do imaginário. São Leopoldo: Ed. Unisinos, 2003.

STERZI, Eduardo. Dante: Um poeta extremamente autobiográfico. Revista do Instituto HumanistasUnisinos.Ano VIII, nº 264, p.25-30, Junho/2008.

TORRES, David. Resenha Beneath the Remains- Sepultura. Setembro/2014. Disponível em <http://whiplash.net/materias/cds/209971-sepultura.html.> Acesso em: 24. Out. 2014. 
ZAMPOGNARO, Carlos E. Dante Alighieri: O Poeta filosófico. São Paulo: Lafonte, 2011.

Original recebido em: 03 de dezembro de 2015

Aceito para publicação em: 15 de janeiro de 2017

Alexandro Buffon

Graduado em história pela Universidade Feevale; mestrando em Processos e Manifestações Culturais pela mesma universidade.

Cristina Ennes da Silva

Doutora em história pela PUC-RS. Diretora do Instituto de Ciências Humanas, Letras e Artes da Universidade Feevale. Professora no curso de História e no Mestrado em Processos e Manifestações Culturais na mesma universidade. 